\title{
The birth of the influencer-activist, a case study from Spain
}

\author{
Pau Munoz ${ }^{1,1^{*}}$ \\ 1*IRG, UAM, Cantoblanco, Madrid, 28049, Madrid, Spain.
}

Corresponding author(s). E-mail(s):

pau.munnozp@estudiante.uam.es;

\begin{abstract}
An activist is someone active towards change in political or overall social matters who may carry her activity alone or embedded in an organization organization such a political party or an NGO. The new political realities of the network society as well as the wide array of technological tools available on the internet has facilitated the rise of a new kind of activist, the "influencer-activist" that derives from the well documented figure of the cyber-activist, who is les embedded in political organizations and for whom online social networks are the main environment of activity, sometimes the only one. I used qualitative research techniques of content analysis as well as deep interviews with key internet figures who self-identify as cyber-activists to articulate a clear definition of the influencer-activist along with a taxonomy of their tools and strategies by exploring their introduction into activism, their main motivations, online communication techniques as well as their relation with traditional forms of communication and activism and political participation.
\end{abstract}

Keywords: digital activism, cyber activism, online activism, online politics, online influencers, online social networks, political communication

\section{Introduction}

We define activism a set of efforts carried out by individuals known as activists, sometimes organized in associations, platforms, NGOs or informal groups aimed towards producing a change in social, economic or political order. Traditionally, activist organizations developed their activities in areas 
they felt lacked enough attention from the establishment, such as environment preservation, women rights, minority rights, anti-racism or poverty but also in some cases men-rights, free market economy or anti-immigration as well[1] [2] [3] . Due to the nature of their activities, activists are used to operate from the margins of the system, therefore they seek to challenge the status quo represented by the mainstream media or the well established political elites by introducing new issues on the political landscape [4] [5]. They carry out their activities at low cost, often combining conventional means of communication and political participation such as study groups, signature collections or campaigns on the press with non conventional ones such as paintings on the wall, text message chains or any form of direct action. The use of new technologies has always been a key aspect for the development of activism [5] [6]. From the first printers, to the telephone network and recently, the internet, activist organizations take profit of any new communication technologies available to them to promote their messages and overall lower the participation costs in the process of recruiting new members and coordinating for actions and campaigns [3]. We see that every major technological revolution, especially the ones directly related to communication has always had its direct effect on political participation and overall political dynamics [7]. Thus, the massive implantation of internet revolutionized the communication processes in society as well as the relationship between citizens and the media as on the internet information can flow directly from the source to the audience, allowing a major degree of transparency, exposure to a diverse set of political ideas and points of view and new possibilities for feedback between the producer and the consumer of news [8]. That moved traditional activist organizations that were focusing on local issues and relying on local resources to a new landscape where they started sharing ideas, resources and strategies online in a global environment, focusing on issues at a global level. Digital technologies lowered the participation costs and expanded the reach allowing the creation and growth of activist organizations [9] [10] and resulted in the creation of alternative spheres of communication serving as counter-powers for the established ones [7]. Those new spheres of communication on the digital space emerged with their own norms and communicative process [7] resulting in the birth of new forms of activism, commonly known as digital-activism or cyber-activism where most of the communication processes if not all are carried out online in forums or online social networks, even some protest actions are carried out entirely online and the number of grassroots activists is expanded at large at the cost of the cohesion and stability of the activist organization [11] [12] [4].

Cyber-activism also known as digital-activism reefers to the use of digital technologies by an individual or a group to achieve social change. In this new form of activism that develops as a consequence of the adoption of new communication technologies by activist organizations [13], social change is achieved by means of an efficient coordination, an expansion on reach limits and a rapid diffusion of new information [9]. This new form of activist emerged along with 
the first internet connections in the 90's and went through a set of different stages or waves as communication technologies evolved on par with social processes all over the world. Athina Karatzogianni [14] explores four stages of cyber-activism. The first one begins in 1994 with the zapatista movement in Mexico and the first anti-globalization protests. During this first wave they key technological factor were telephone networks, the first internet connections for an effective coordination as well as the first portable photo and video devices that allowed to start recording footage during protests and claims for a later sharing. The next stage comes between 2001 and 2007 with the antiwar in Iraq protests. In this wave we find the first consolidate forums and blog networks to be a decisive mean for generating counter-narratives and for effectively coordinating and mobilizing activist organizations on the ground. The third stage starts in in 2007 and goes hand in hand with the economical growth in countries such as Brazil, Russia (and its area of influence), China and India (commonly known as BRICS) blog networks and forums were a decisive factor in organizing complains and protests against corruption and authoritarianism and, played a role in protests such as the color revolutions in eastern Europe. The fourth wave appears in western and Arab societies between 2010 and 2013 and can be associated with phenomena like Wikileaks, the Spanish $15 \mathrm{~m}$ protests the worldwide Occupy movement and the Arab spring [4]. Online social network platforms such as twitter, YouTube and Facebook started to gain traction worldwide around 2009-2010 and caught the eye of many activist organizations and individuals who saw a great potential for coordination in them. This fourth stage of cyber-activism is characterized by a heavy use of social networks for tasks such as narrative diffusion, protest coordination, rapid and sometimes personalized news distribution (ex: news based on the city where the protest is happening). Precisely due to this massive use of online social networks these protests experienced a tremendous success during their first days due to their facilities in recruiting participants by social media but failed to consolidate in structured and cohesive organizations [12]. Internet was the origin of most of the protests related to this wave, some forms of protest that appeared here didn't even move offline that is the case of hashtag-protests or change.org campaigns other forms of protest started online with an online target as a goal such as the case of cyber-attacks like DDoS carried out by so called hacktivists [15] [16].

The last stage mentioned by Karatzogianni involved a step rarely seen in the other waves. Protests such as the Occupy movement, the Spanish 15m and the ones related to Wikileaks and the Snowden affair made a huge impact in the political agendas. Traditional political parties started listening closer to the claims both on the street and particularly online and some prominent activist figures that gained relevance by their social connections and "virality" online used their newly gained social capital and jumped straight into mainstream politics. By carefully looking at the evolution of the political landscape in western societies after 2014 and until now, we have reasons to define a new wave of cyber-activism that started after 2014 and is mainly characterized 
by events like the 2016 elections in the USA or the Brexit or more recently the covid19 outbreak [17] and by new forms of populism offline but especially online [18] [19] [20]. In this fifth wave of cyber-activism the figure of the activist evolved from the $15 \mathrm{~m}$ / Occupy activist that was mostly left-wing or even not interested in specific political ideologies, used social networks mostly as a tool to call to action on offline protests or just to protest and lacked a structured network or a clear agenda to a new kind of cyber-activist more individualistic, less focused on street protests and offline activity, well aware of the fragility of online environments, more alienated with established political ideas both left and right-wing and most of all, with a clear goal of generating a change in society by pushing a particular ideology. Specific goals include pushing a particular issues (such as related to taxes, abortion, feminism or immigration) into political programs through online actions or most of the times by getting out the vote for a particular candidate or political group [21] [22]. Frequently these cyber-activists were less integrated in structured activist organizations and resembled the figure of the so called "influencer" [23], that is, an individual that "speaks the language" of the younger generations [24], has a large follower base that posts content related to a particular field (ex: sports, music, tech...) and has a great potential for influencing to her audience by recommending them products, services or in this particular case political ideas or perhaps even candidates.

To my knowledge, though this a very interesting figure that plays a key role in modern-day political communication and overall online social networks and protest dynamics, this new influencer-type cyber-activist or influencer-activists is still an under researched topic.

In the following work I shed light on this character in a qualitative manner by studying how the influencer-activist forms her ideology, her motivations, tools and techniques as well as her relationship with traditional mass-media, political parties and other activist individuals or organizations. In order to study and comprehend the main features and the political behavior of this new particular kind of cyber-activist that coexists with other forms of activism I conducted semi-structured interviews with 17 self-proclaimed cyber-activists who correspond to the profile of the influencer-activist that can be defined as:

Definition 1 (influencer-activist) An influencer activist is an activist who is very active on social media, Not an affiliated member of any political party nor work for any conventional mass-media in an exclusive manner, bases the major part of her activism on social media, is highly conscientious and very vocal about her political views and ideas and performs campaigns individually or collectively to push certain topics into the political agenda by using a variety of tools and strategies both online, offline or in a hybrid manner.

The interviews were conducted with Spanish individuals who complied with the aforementioned definition 1 which is of particular interest due to the relevance of cyber-activism in the country and many phenomena that happened in 
Spain such as the $15 \mathrm{~m}$ protests and the "indignados" movement where social media, specially twitter was a fundamental coordination and execution mean [25], along with the rise of populist parties [26] [27] [28] and new forms of political communication from both left and right wing organizations in the Spanish Twitter-sphere [29].

\section{Research approach}

Thus, better comprehend the phenomenon of the influencer type cyberactivism I formulated the following research questions:

- RQ1: How does an influencer-activist form her ideology?

- RQ2: What motivates a influencer-activist to perform her activism online?

- RQ3: What are the tools and techniques used by influencer-activists when promoting their messages?

- RQ4: How does a influencer-activist interact with opposite activists online?

- RQ5: How does a influencer-activist interact with conventional media?

- RQ6: How does a influencer-activist interact with political parties?

That I will answer along this work.

Participant identification: I began detecting cyber-activists that would fit into the category of the political influencer by browsing through social media profiles related to Spanish right-wing organizations like Students for Liberty, Instituto Juan de Mariana or Fundación Danaes and left-wing organizations such as Instituto25m, Rebeldiajoven and Sindicato de Estudiantes inspecting their followers, the recommended profiles associated and their interactions selecting users that complied with Definition 1 1. Then I complemented the list by browsing through well-known political twitter accounts that usually support the ideas or are linked to political organizations or mass medias such as @clubdeviernes, @CapitanBitcoin, @EugeniodOrs_or @FrayJosepho on the right-wing spectrum and @spanishrevorg, @kaosenlarednet, @Shine_McShine or @protestona1 on the left-wing spectrum. The browsing process involved inspecting the most recent publications one by one on those profiles detecting and following the quotes and mentions to other profiles as well as following the twitter recommendation algorithm to find similar users. The list was also complemented with profiles found at portals such as batallacultural.com which provides a curated list of right-wing cyber-activist along with their social networks and redrepublica.es that provides a list of left-wing anti-monarchy hashtags that can be used to detect twitter users on the left. Once the initial list was complete I looked for political focused, active and popular profiles so I proceeded to filter for the individuals who complied with the following conditions:

- Complies with the Definition 1

- At least one year of continued activity

- Focused almost entirely on topics related to political or social issues

- More than 1000 followers on one of their social network profiles at least 
- An activity pattern of at least 5 publications a week across all of their social network profiles

The first condition was assessed in a qualitative manner, the other ones in a quantitative manner.

The last step involved a manual revision of the most prominent profiles to identify potentially interesting relations and communities and hierarchies amongst the activists thus allowing me to identify the most potentially relevant cyber-activists to be interviewed. Screening participants: I then proceeded to contact the selected individuals. The approach was made by Twitter direct messages, Instagram direct messages or provided e-mail addresses. The interviews were conducted in-person in Madrid or online using the ZOOM app according to the geographical and temporal availability of the activists. The interviews were audio recorded and transcribed verbatim, verbal consent was obtained from all participants prior to the start of the recorded interviews. Interviews ranged from $30 \mathrm{~min}$ to $180 \mathrm{~min}$, with the average interview lasting $40 \mathrm{~min}$. Interview format: The interview structure was composed by three blocks. On the first blocks I asked the participants about their main motivations, that is how they formed their ideologies, the role of internet on their ideology formation process and their transition into cyber-activism. The second block involved questions related to their tools and methodologies. I mainly asked about the role of digital technology in their activism and the set of tools and social network sites they were used to along with the specific use case for each. I also asked about the methods and techniques and strategies they use to promote their narratives and perform their activism online I payed special attention to activist recruitment, action coordination and content viralization. On the last block I asked questions related to their relationship with traditional forms of communication and political participation such as political parties, the mass media as well as their relationship with opposite forms of activism.

Demographic data: At the end of the interview a small survey collected features such as age, gender, declared ideology, education attainment and occupation.

\section{Results}

A total of 17 interviews were conducted in 2021 from January to October. The demographic features of the interviewed individuals can be found in table 3 . 


\begin{tabular}{|l|ll|}
\hline \multicolumn{4}{|c|}{ DEMOGRAPHIC DATA } \\
\hline Mean age: & N & $\%$ \\
\hline GENDER & 13 & 76 \\
\hline Male & 4 & 24 \\
\hline Female & & \\
\hline IDEOLOGY & 3 & 18 \\
\hline Self identify as communist & 4 & 23 \\
\hline Self identify as socialist & 4 & 23 \\
\hline Self identify as conservative & 3 & 18 \\
\hline Self identify as libertarian & 3 & 18 \\
\hline Self identify as anarchist & \multicolumn{2}{|c|}{} \\
\hline EDUCATION & 4 & 23 \\
\hline High school diploma & 1 & 6 \\
\hline Vocational school & 10 & 59 \\
\hline University degree & 2 & 12 \\
\hline PhD & \multicolumn{2}{|c|}{} \\
\hline OCCUPATION & 7 & 41 \\
\hline Student & 4 & 23 \\
\hline Freelancer & 1 & 6 \\
\hline Engineer & 2 & 12 \\
\hline Public servant & 3 & 18 \\
\hline Journalist & 1 & 6 \\
\hline Political analyst & \multicolumn{2}{|l}{} \\
\hline
\end{tabular}

Demographic data related to the interviewees

The interviewed individuals used a variety of social networks that are summarized in table 3

\begin{tabular}{|l|rr|}
\hline \multicolumn{3}{|c|}{ SOCIAL MEDIA USE } \\
\hline Social network profiles & N & $\%$ \\
\hline Facebook & 6 & 35 \\
\hline Instagram & 10 & 59 \\
\hline Twiter & 17 & 100 \\
\hline YouTube & 8 & 8 \\
\hline Twitch & 6 & 35 \\
\hline TikTok & 3 & 18 \\
\hline Telegram channels & 4 & 24 \\
\hline Tools and communities & \multicolumn{3}{|c|}{} \\
\hline Telegram groups & 4 & 24 \\
\hline Whatsapp groups & 12 & 71 \\
\hline Patreon profiles & 5 & 29 \\
\hline Paypal profiles & 3 & 18 \\
\hline Discord servers & 4 & 24 \\
\hline Personal websites & 2 & 12 \\
\hline Linktree profiles & 7 & 41 \\
\hline
\end{tabular}

Social media and tool usage among the interviewees

\subsection{Ideology formation}

The first research question involves understanding how this new kind of cyber-activist develops her ideology. Historically, activists developed their 
ideology through a set of personal experiences offline such as experiences with poverty or any form of discrimination or perhaps access to knowledge that allowed them to form a set of opinions and to see the world through a particular ideology [1] [30]. This first research question involved studying the ideology formation process of this new type of activist carefully examining the role of internet and online social networks in particular during the process to understand their importance or the lack of it.

RQ1: How does an influencer-activist develop her ideology?

The majority of cyber-activists I spoke with started getting interested in politics at an early age, most of them during high school or their first college year. Most of them stated that they got introduced to their ideologies by a close friend or relative, something that resembles the traditional introduction into activism [3]. They then proceeded to reinforce their ideological points of view by themselves by browsing through content in online news sites such as hyper-partisan medias, forums and mostly YouTube channels and twitter accounts. As one of the influencer-activists noted:

"I remember that as I started university I made a bunch of new friends. One of them was so much into politics and economy, I've always had curiosity towards politics in general, we started talking and he introduced me to the Austrian school of economics by pointing me to books and online recorded conferences. I think that was the key moment. After that, I started to read about liberalism and watch videos on YouTube. It went uphill from there since now." - Subject 2, conservative

Some of them put more focus on their personal experiences though the role of a close person in the form of a friend or a colleague is recurrent. Such is the case of one of the activists that were interviewed, a left-wing "YouTuber" and a very active Twitter user.

"As a kid I lived in a really poor neighborhood I saw a lot of inequality and I experienced poverty myself. Then I moved to London where I started working as a waiter, the working conditions were far from good and I started complaining. At some point I realized that the rest of the workers there did listen to my complains and we were sharing our problems. One of the folks there was an activist in an organization tied to the labor party. He introduced me to other people and I guess my activism kinda started there. I started reading, meeting people as well as participating in Facebook groups. When I returned to Spain I started getting in touch with other socialist Spanish people." - Subject 5, communist

Other relevant aspects presented by the interviewed activists comes in the 
form of a natural curiosity towards political topics and ideas as well as a desire to get involved in social matters. As pointed by one of the subjects, a girl heavily involved in economical and political liberty activism:

"I've always felt a big curiosity about politics in general. When I started university I actively looked for opportunities to get involved in student associations I was lucky that a classmate introduced me to this association, that was the first of many steps I took." - Subject 10, libertarian

After being introduced into their political ideologies in an off-line manner the totality of the interviewees stated that they continued to develop their political ideologies in an online manner mostly and occasionally by sharing book titles or websites and commenting ideas offline with their friends. When it comes to their online activity some of them pointed to online forums and hyper-partisan medias though the majority signaled Google searches and online social networks such as Twitter, YouTube and Facebook groups as their main way of getting political content. When asked about the reasons of so, they pointed the ease of use and the facilities for getting new related content recommended to them by the social media recommendation engines.

"Of course the internet played a role when I developed my political ideas. I didn't use "internet forums" a lot, I mostly got my information from YouTube, Facebook groups and specially Twitter. I remember I would watch a conference on YouTube and the site would point me to new authors or YouTubers through the sidebar. I would spent a lot of time there even without realising it." Subject 6, socialist

When asked if they used to actively search or even just occasionally saw content relate to opposite political views some of them replied affirmatively and some negatively. Those who did not search for information related to contrary points of view generally blamed the social media algorithms, others just said straight that they were not interested in contrary points of view.

\subsection{Introduction to activism}

Traditionally, activist individuals started into activism straight away almost along with their ideology formation process aiming towards a change in society's values and moral standards [31], as their activity was embedded in an offline cohesive organization [1]. Though these patterns still well-explain the experiences and activities of a large amount of activists this new kind of influencer-activist presents specific dynamics such as the fact that their ideology development process may kick-start offline but develops mostly online, with a less structured and cohesive offline network and connected with other like minded individuals in a purely virtual manner. 
RQ2: What motivates an influencer-activist to perform her activity online?

The majority of the individuals started their activism online when they felt they knew enough and had a solid ideological fundamentals about the topic they wanted to talk about to offer some "relevant and useful content" as they said. Their online activism was mostly inspired by other activists who they were following on online social networks such as Instagram, TikTok, YouTube, Facebook but mostly Twitter, YouTube and Twitch. They saw those other activist figures as influential and popular figures and thought that "if worked from them then it might work for me". As one of the interviewed subjects stated:

"As I started following political influencers and activists online I started thinking that It would be so cool to do that someday. I've always been good with computers and I taught myself how to use editing programs then I started this YouTube channel I don't know where it will go but is a fun thing to do and if it helps some other people exit the matrix it's enough for me and who knows where it will lead me." - Subject 11, libertarian

We can detect intrinsic and extrinsic motivations when it comes to creating political content online thus complementing related studies [32]: On one hand the interviewed activists use social media as a way to express themselves, a space that allows them to be creative and receive feedback (The majority of the interviewees, specially the ones who started on video platforms such as YouTube or Twitch started with their online activism as a hobby.). On the other hand social media also allows them to gain popularity and to develop personal social networks, that may provide them with professional opportunities later on. We can also detect a certain bandwagon effect when it comes to them joining political ideologies and starting to post content as they perceive that they will make them quickly gain attention.

When asked about the particular reasons that moved them towards being politically active online they appealed to their desire to elevate the morals of a society that is overlooking important issues such as women's rights, LGBT community rights, fight on poverty, protection of the environment, racism, economic liberty, religion or immigration. Some of them, mostly the ones identified with right-wing ideological positions, appealed to the need to fight a "cultural battle" against the "mainstream media" and "the political ruling elites" as they called it, that is, to generate a particular counter-narrative against the one that is being pushed by the main Spanish mainstream medias and the ruling political parties. When asked about that "cultural battle" concept they pointed at online social networks as their main "weapon". As one of them stated:

"Of course there is a cultural battle, don't you see? The Spanish mainstream media is clearly left-wing, pro-taxes and anti-Christianity, they are well 
aligned with PSOE (currently in the government). Social networks are the only space that's left for us, we can expect nothing from television networks." - Subject 12, conservative

As the traditional off-line type of activist focuses her activity offline in a local context these new influencer-activists focus theirs online and sometimes they even push for offline actions. When asked about the core motivations of their activism the majority of them contemplated offline actions such as demonstrations to push their issues in the political agendas of the ruling parties or perhaps to force some companies take a particular action but the vast majority of them stated that their main goal was to produce a change in the collective conscience that is, not to incorporate a particular issue in the political agenda of a party but to en-root a particular set of ideas into the conscience of the average individual in a gramscian way [33], making them demand a particular set of political organizations in the future. As one of the right-wing libertarian activists said:

"Fighting the cultural battle means making people accept new ideas. In Spain you can't talk about tax-cuts and there can be a debate about that. This country won't progress unless we start taking full responsibility of our actions, we need a change in the collective conscience." - Subject 12, conservative

To summarize their aspirations. They try to develop a collective conscience towards an issue by embedding their particular cause into the context of a full set of ideas (ex: taxes - liberalism, anti-racism - socialism), they try to perform agenda-setting for their particular causes forcing political organizations talk about certain issues and overall they try to provide alternative interpretations and behavior around a particular issue at the societal level.

According to their experiences, they used to present very stable publication patterns focused on their particular topics at their starts, and then as time passed and their profiles started to grow. At some point, they were offered to take part in specific activist networks. That process happened entirely online and usually started by an introduction and an invitation by a direct message on sites such as Twitter or Instagram followed by an invitation to take part in a closed group on WhatsApp or Telegram. Some of the interviewed activists also mentioned that the invitations to take part in organised groups on WhatsApp or the liked eventually led to invitations to join offline events such as demonstrations or conferences or to join political organizations or to write or speak in conventional mass-media.

Similarly, as the activist grows in popularity she may start receiving some revenues due to donations or embedded ads on videos and the like and thus starts looking at the platforms more carefully, knowing her followers well and considering the possibility of self-financing to dedicate all of her efforts 
to the cause. Platforms such as YouTube, Twitch or Patreon are used for that and will be inspected in more detail in the next section. As the activist starts receiving revenue or considering so, she starts professionalizing her activity. Professionalization comes by a clear differentiation and inter-relation of content between platforms, more strict posting routines, an enhance in the quality of multimedia material and the effort for providing more carefully curated material to their audiences.

"Once I started getting money for my activity stuff changed a little bit. I feel that I have to post every day and to comment major political happenings. It good though sometimes a bit stressful, you know it's like a job now." - Subject 12, conservative

Other remarkable aspects include a moderation in their narratives and occasional conflicts and controversies with other activists who are not receiving revenues. As one of the interviewed states:

"Since I started receiving money from Patreon and YouTube I've been criticized by some of my colleagues who told me that I "sold myself" to the system. I don't like it either, but you know, I think that I'm able to reach way more people and push for a greater change this way." Subject 5, communist

On the other hand, other interviewees talked about the relationship with their audiences and how they push them into a particular discourse:

"Since I use Patreon I get in touch a lot with my audience but I think that I live in an echo chamber, they demand a kind of content and I have to provide it to them I don't know if I'm convincing them or they are convincing me I feel that if someday I change my mind on any political idea... that may have a cost you know." Subject 12, conservative

Finally almost all of the interviewed participants expressed preoccupations about a possible loss or as some of them refereed "censorship" of their social media accounts, especially the ones with more radical discourses. As one of them said:

"Yes though I've never lost any account I'm worried about that. That happened to a colleague of mine and to this day he still doesn't know the reason. What will I do if I lose my accounts? I'm living out of this." - Subject 15, socialist

The ones who are also involved in some way with conventional organizations also stated that since they are now "public figures" they have to moderate their activism in order to integrate it into their political organization and effectively maintain the relationship. Some of them (a minority) also stated that as they grew in audiences they had to start appealing to a large and a 
more diverse base of followers so they had to moderate a little bit.

We can summarize their development into activism in the following diagram. 
PERSONAL BACKGROUND

The individual went through personal experiences that make her develop a particular vision of reality.

Offline experience: A friend, a colleague or a relative introduce

\section{CONSCIENCE DEVELOPMENT}

her to a particular ideology.

The individual starts developing a vision of reality according to a particular ideology. Her personal experiences are now interpreted through a system of ideas.

Ideology reinforcement: The individual reaches for political

content onlinein news sites,

\section{IDEOLOGIZATION}

forums or social networks

The individual now comprehends the fundamental aspects of the presented system of ideas. Not only sees her problems through her ideology but also more general social problems as well

\section{INTRODUCTION TO ACTIVISM}

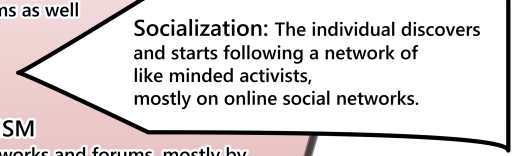

The individual starts to become active in online social networks and forums, mostly by reading content and reacting to it by likes, reposts and occasional comments.

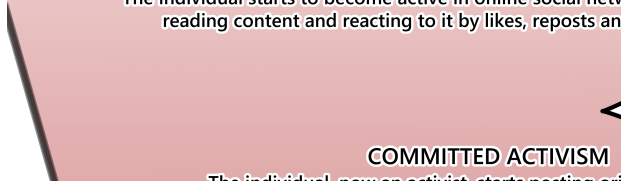

Activism: Due to her personal context and inner motivations, the individual

COMMITTED ACTIVISM

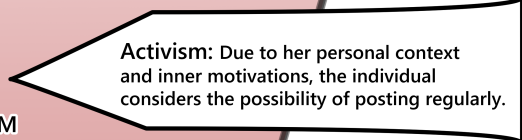

The individual, now an activist, starts posting original content on a regular basis. The posting frequency rises and her social media profiles start to become well-known amongst the community.

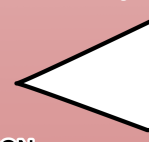

Integration: Due to her success, other activists reach out and offer to integrate her into a network.

\section{NETWORK INTEGRATION}

Starts coordinating actions online and sometimes

offline as well. Her patterns of activity become

more stable. Her content is more structured and organized.

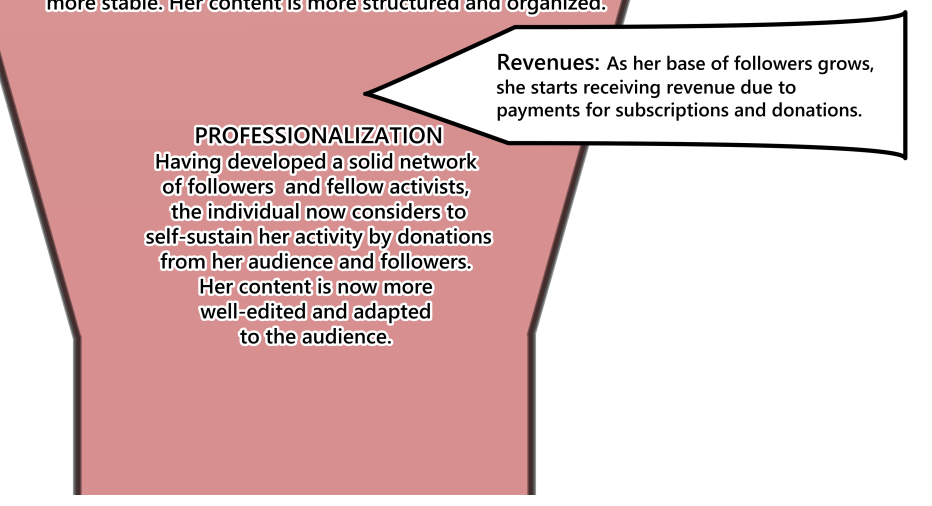

Fig. 1 Influencer-activism funnel 


\subsection{Tools and methodologies}

New technologies have been the main factor for the rise of this new kind of political activism. These new influencer type of cyber-activist proves to be very able in the management of a variety of online social networks and digital tools. They are very aware of their possibilities, prove knowledge about posting strategies and even about the mechanics of some recommendation algorithms. To get a deeper knowledge on how these activists function in online environments we need to start by knowing their tools. In this subsection I will answer the following question:

RQ3: What are the tools and techniques used by influencer-activists when promoting their messages?

\subsubsection{Online platforms}

The influencer-activists that were interviewed in this research are active in the following online social networks:

Twitter: This is often the main social network of choice amongst the activist community, all of the interviewed persons are active on Twitter. In general terms, they use it to reach their audiences with ideological content, to quickly react at social or political events, to perform calls for action in the form of hashtag promotions and the like, to engage in political debates and as a central point where they can diffuse content created in other platforms, pointing their Twitter followers to follow them on other media as well.

Facebook: A social network that is falling in disgrace. The interviewed influencers who have been active online for the most time signal this platform as one of their main entry points into political activism though they almost don't use it now. When asked they state that Facebook private groups where a key point in developing a sense of belonging as well as well as a political identity.

TikTok: This network is a novelty for most of them, for what the interviewed activists answered, this is probably one of the less political social networks for now though some of them are starting to use it as a way to mix their personal life with their activism and thus reach wider audiences.

YouTube: Many of the interviewed activists use YouTube as their main communication channel when it comes to promoting their narratives as this platform allows them to create long and lasting content, to develop ideas in detail and to report and comment real life events quickly. The ones who use YouTube state that they use it when they want to develop and share a solid informed opinion on a particular topic. Usually the videos shared on this 
platform are promoted later on via Twitter as well as Facebook.

Instagram: All of the interviewees who use Instagram use it as a mean to embed their political rhetoric into their daily life by combining. As a christian activist girl said:

"I use Instagram as both a mean to talk about my daily life as well as a mean to promote my political message. As my message is a bit controversial these days I like to show that you can be a religious person and have a normal life at the same time, you know, go to pubs on Friday and go to the church on Sunday." - Subject 16, conservative

Twitch: Twitch is seen as a social platform that is rapidly gaining traction among the cyber-activists. They use it as a way to create fast content related to very recent news as well as hot social topics. Most of them often re-use the content created during live streams in twitch chopping it and uploading it directly into other platforms like twitter or YouTube expanding the impact of their message. They tend to prefer twitch over platforms such as YouTube due to the fact that they perceive twitch to be more transparent, less censoring as well as more viable in terms of economic interactions with their audience. The platform YouNow is was also mentioned and it's used the same way as Twitch.

\subsubsection{Tools}

Along with their social media profiles of choice they also presented some digital tools that complement their presence in social networks in their online activism.

Whatsapp: Mostly used for activist to activist coordination via private conversations or tight-knit groups. Sometimes as the individual starts gaining traction on social media she gets invited to participate in those groups.

Telegram: Telegram is used both as a distribution channel for political narratives via Telegram channels as well as a tool for activist to activist coordination via private groups or perhaps activist to followers coordination via public or semi-private groups (invite only) groups.

Discord: Is a complex tool used for setting up communities formed composed by the activist, their inner circle and part of their audience. The tool allows the creation of diverse chat rooms commonly dedicated to a variety of topics such as the discussion of a set of political ideas, sharing and commenting news or even coordinating for some actions. The tool also facilitates the sharing of multimedia files such as videos or PDF files easily allowing the exchange of political texts and ideas. It also allows diverse user roles such as of content moderators and administrators which in this case use to be very active users close to the inner circle of the activist, sometimes other influencer-activists as 
well, this way allowing a particular hierarchical structure as well as the formation of collective identities [34]. To our knowledge this tool is often the haven of the hard-core activist circle where the most dedicated individuals discuss ideas and actions. As one of the interviewees a conservative activist stated:

"So whenever I find a user that uses to be active during my live streams on Twitch, sometimes I invite him to join the discord server we have here. We use to comment news and discuss authors, sometimes we stay up till 3am talking about a single book..." - Subject 4, conservative

Patreon: Is used as a tool that allows users to get revenues and self sustain their online activity. Their audiences can subscribe to their content by using this tool paying an activist defined monthly fee. Subscribers to this service use to get custom or premium content from the activist such as exclusive videos. Sometimes they have the chance to influence the activity of the account owner by interacting with him via private messages. This is also used by activists as a mean to identify the most political active followers and recruit them into other private or semi-private groups to introduce them into activism in some manner.

Paypal: Is used as a tool for receiving donations. Some activists provide Paypal custom links in their social network profiles and regularly ask for donations to self sustain their activities.

Linktree aggregates: Is a tool that allows users to generate a custom page containing links to other websites. Some of the interviewed activists use it to list all of their social media profiles in one single places, to make it easy for new followers to get in touch with their online presence.

In summary their online presence can be represented as in the following diagram: 


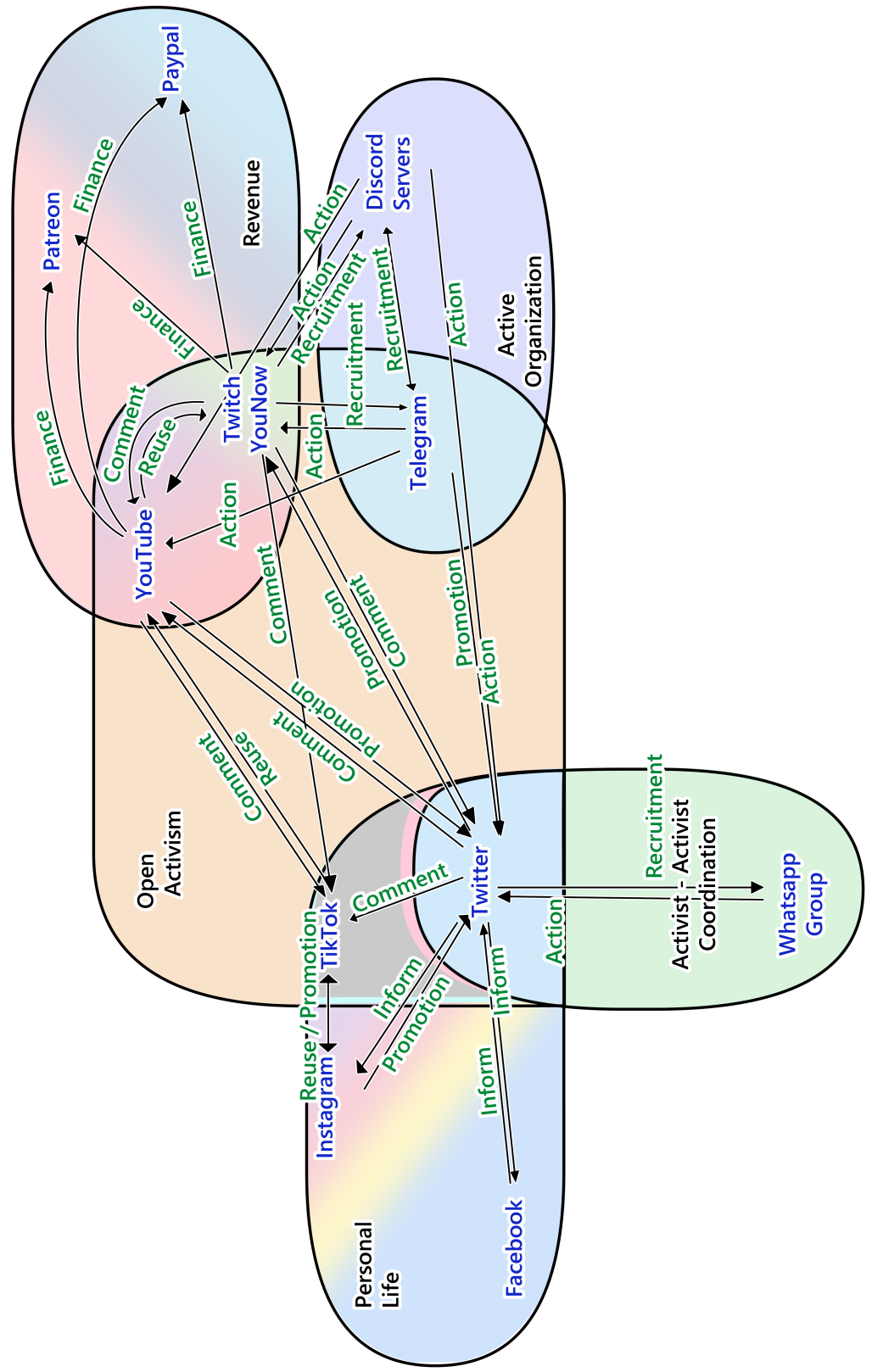


In this case, we see that technology is not the main enabler but the main reason for this type of activism [9] [7] and that social networks are used in a scheme of cooperation and competition as the activists are well aware of the potentialities of each network due to their particular differentiated functions [35]. They integrate each platform in their own custom network and adapt the result to their own political goals.

As we can see, Twitter being the classical tool of choice for many kinds of influencer-activists [36] [6] appears to be the central online social network for most of the interviewed activists, they use it to comment on topics of relevance and engage in debates or promote actions and to point their audience to other social networks. We see a clear division of social networks such as Facebook, Instagram, TikTok or sometimes Twitter that act as spaces of personal life that is, platforms less politically charged where the activist fundamentally posts about her personal life. Then there is a more general set of apps that might function as an open channel of some sort where the individual is active in spreading a particular message by tweeting claims, publishing politically charged videos to educate the audience, ranting about relevant happenings on Twitch or sometimes even dancing to the partisan beat on TikTok [37]. Professional activists who are getting revenues from their online activity add a new set of tools into their networks. They usually take profit of their large base of followers on Twitter but specially on sites such as YouTube or Twitch to ask for revenues in the form of subscriptions to Patreon or donations through Paypal. The last set of tools involves the set up of custom communities on places like discord or private or semi-private groups on Telegram that go beyond calls for action and narrative distribution [34] but are used to recruit and educate a hard-core base of followers that will mostly be prone to follow if not propose online and offline actions from trending topic or change.org campaigns to street protests or actions of citizen journalism. Thus we can define five main kinds of relationships the activist can hold with different platforms: inform where the activists simply lets others know about their profiles or the profiles of other users of interest on other platforms, comment where aside from that the activist also comments specific publications to signal their relevance in a positive or negative way, promotion where the user not only informs but actively encourages their follower base to follow and interact with the rest of their profiles, recruitment where the activist identifies, selects and incorporates parts of their follower base to more tight-knit groups and finally action where the individual coordinates with other activists, commonly by using closed or semi-private groups to perform online actions not limited to narrative promotion but also ones such as censorship attacks, hashtag hijacking [38] or trolling campaigns against their adversaries [39].

\subsubsection{Techniques and strategies}

Along with the aforementioned tools comes a set of techniques and strategies utilized by these activists in order to make the most of them in spreading their political messages. 
As mentioned earlier, the interviewed individuals were very aware of the potential of online social networks and overall internet to generate new communication spaces and to bring politics into every aspect of social life [40]. Some of them were very conscious about the fact that the internet is one of the few if not the only space were they are able to push for their particular narrative [4]. They also take profit of the ubiquity of electronic communication devices and social interactions through digital means to generate a particular environment were they interpret many aspects of their and their follower's daily lives through the political lens of their discourses. When asked about the kind of content they choose to post online most of the interviewed individuals stated that one of the main aspects of growing a successful profile on social networks is to be very specific, to post regularly and if possible to post in a particular time window. As one of the left-wing activists said:

"Yeah I don't do a lot really, it's not that hard. You just need to focus and be very active, to be constant and to do your posting late in the evening, so people will see it after work." - Subject 1, socialist

Another fundamental aspect of their online communication strategies is to be very aware of all of the mainstream news, the political happenings and any form of social controversy to be quick in commenting them. As one of the subjects told us:

"If something big happens like I don't know, the government told a fake new, another corruption scandal or such and you are the first commenting it, chances are you'll go viral and that brings a lot of new followers, so yes I'm very aware." - Subject 12, conservative

Whenever a relevant event happens and it is pushed in the news, most of the activists are quick to develop analyses and interpret them through their own ideological lenses, time is a critical factor. During the process, sometimes the actual events that happened and became news can lose their original form to adapt to a particular narrative. In extreme cases, some activists may even deform reality to the point of creating false news also called "fake news" just to push for a particular topic and spread propaganda.

Finally, the last publication strategy carried out by individual activists solely by themselves involves getting in controversies, debates or overt aggressive discussions over online social networks. Those happen majorly in networks such as Twitter in the form of replies, quotes and mentions, on YouTube in the form of criticism over videos and on Twitch in the form of call-outs and criticism. They signal that whenever they get in these controversies, most of the times they experience a growth in interactions such as views and followers. As one of them admitted: 
"Each time I get involved in a debate with a journalist or an activist of contrary sign I get a boost on followers, it is what it is. And though I don't like to be involved in these things myself I'm pretty sure that some of the well-known activist figures are regularly using this as a technique." - Subject 15, socialist

When they act in a collective manner that is, they coordinate with other activists, their audience or both we can appreciate that their strategies fit mainly into three categories that is financing, recruiting and political action.

As commented earlier, the influencer type of activists actively explore the possibilities of all the tools they detect to integrate them in their network in the best way. Very often, whenever they feel they have a chance to do so, they would start enabling their online content to be "monetized" that is, to start receiving revenue according to the number of visits they get. YouTube is the main platform used for that, but as some of them point, it may not be the best platform for do so. As an interviewed activist noted. They usually start on YouTube to grow a base of subscribed followers to then point them to other platforms such as Twitch or Patreon.

"I try to monetize my content as much as I can, but with platforms like YouTube sometimes is hard... If I curse of try to show certain videos (talking about police brutality in his particular case) the platform would de-monetize my channel for some days and that poses a problem... so I prefer to talk about to show certain things on other platforms." - Subject 11, libertarian

Some of them complement their activities by asking for donations through Paypal though Patreon is the main choice when it comes to get revenue for their online activity though some of them are worried about the sacrifices the might need to do in terms of constancy in publications and the kind of content. The ones that use Patreon amongst the interviewees, signaled that they started to use it once they knew they had a very solid base of followers. When asked about how did they know about that group of followers they answered that they noticed a set of users that were regularly liking and commenting their tweets and videos even sending direct messages to them.

Coordination among activists usually happens in private WhatsApp or Telegram groups. Their actions involve hashtag campaigns aimed towards making a particular hashtag to be trending topic to maximize the visibility of a particular issue. Some examples include asking for the resign of a politician, pushing towards a boycott to a company or demanding attention attention to the government for a political issue. Some activists have also been directly involved in pushing hashtags / topics related to political parties during political campaigns though not being directly tied to these political organizations.

Other aspects of activist-activist coordination involve re-posting content of their colleagues and comrades to promote it and help them grow as well 
as recording videos together or participating in live streams in each other channels. During our interviews some activists pointed us to a particular action carried out on Twitch called Raid, where a user that is live streaming content would direct their audience into the other's streamers channel so he can make her audience known him help her grow in popularity.

"So if I see that someone is creating quality content and we get along well with each other in my case I will try to help him grow I have no problem with inviting people to talk here on my channel even if they don't totally agree with what we say here." - Subject 12, conservative

Coordination also happens between the activist and her audience. According to the opinions and experiences of the interviewed individuals this happens usually in two forms in a formal and in an informal manner. Informal coordination usually happens when the activist quotes or signals a social cause, like a change.org campaign or a hashtag to promote or an event to attend and her audience gets the signal and seconds the action [11] [2]. Formal coordination happens when the activist has some experience on the platforms and is well aware of her audience. She would identify relevant active figures among her audience and recruit them into private or semi-private groups in applications such as Telegram groups or Discord communities [35].

Once embedded in those groups, the activist will grow her own network and use it to better coordinate offline and online actions. An interviewed activist admitted that those groups often serve as means to coordinate hostile actions against opposite political activists or any political actor in general with the aim of closing social media accounts, flooding opposite hashtags or trending topics with noise or just trolling their rivals.

When asked about those hostile actions most of the activists both leftwing and right-wing expressed preoccupation about them, signaled opposite activists as responsible and stated that them and their friends use to be the targets.

\subsection{Relationship with opposite activists}

The networked spaces of communication online are characterized by the availability of information and its distribution at a very high speed [41]. In the same way, these new spaces are wall-less that is, contrary opinions and points of view can collide at anytime. While traditional activists were used to cooperate or collide mostly on the street in public demonstrations or similar events the internet allowed new kinds of interactions. During the first waves of cyber-activism as defined by [42] activists would interact with each other by comments in blog-posts or at forums. The nature of those platforms would allow a certain 
degree of moderation and the interactions would not be so fast and frequent. Opposite activists would usually prefer to write blog posts criticizing their rivals rather than to storm their blog posts with aggressive comments. The technical possibilities of blogs and forums would allow content moderation so the influencer-activists would mostly be stuck to their own spaces of communication. After the rise of online social networks such as Facebook, Twitter or YouTube those dynamics changed as the new platforms are open by definition, not owned by any particular group of activists, harden content moderation and facilitate fast and anonymous content production [4] [43].

While it is clear that an activist of a particular ideology will think that her point of view on the issues of interest is the right one, she can relate to and interact with the rest of the activist community in many ways. To better comprehend the interaction between activists of opposing points of view in the context of online social networks I asked the following research question.

\section{RQ4: How does an influencer-activist interact with opposite activists online?}

Among the interviewed activists, the ones who hold more radical points of view or the ones who are most committed in spreading their messages appear to be very worried about the possibilities of getting banned from online media, especially due to organized actions carried out by their rivals in activism. Almost all of them were particularly worried about being banned from sites such as YouTube and Twitter.

A group of the both left-wing and right-wing interviewed activists clearly acknowledged that some of the activists in their close circle set up and maintain social media groups in platforms such as telegram where they coordinate what they call "censorship actions" against opposing activists. They are also aware of their counterparts doing the same thing. As a left-wing activist stated

"They closed my account two times and the last time it took me one month to take it back. I'm aware that the far-right is well organized on this, they have their Telegram groups where they coordinate for massive reports on Twitter accounts or they just jump in online debates to insult their adversaries..." Subject 6, socialist

Those actions include massive reports of content posted on the aforementioned platforms arguing copyright or hate speech reasons. Other actions include the rapid gathering of supporters in case there is a hot debate going on on any of the platforms, in that case activists themselves or their deputies demand the attention of their followers in online closed groups in whats app or telegram calling them to action in a particular publication. 


\subsection{Relationship with conventional press}

Starting during the first waves of cyber-activism in the 90's, activists have always looked at traditional media with suspicion and distrust, as they perceived them as agents of the status-quo closely related to the political elites. The early history of cyber activism has been characterized by the tendency to set up alternative communication spaces by using online technology with Indymedia [44] as a clear example. These new cyber-activists still see traditional mass-medias as to be sold to the system though they tend to adopt a different strategy, assuming possible ideological contradictions and prioritizing the maximization of the spread of their message.

To better comprehend this relationship I answered the following question:

\section{RQ5: How does an influencer-activist interact with conventional media?}

When studying the relationship between this new type of activists and conventional media such as the press, radio or television networks we appreciate a two-way relationship.

In general most of the interviewed were critic with conventional media, some of them, the ones more related to populist points of view were very critic accusing them to be "sold to the ruling elites" and have "no potential for pushing societal change" as it's usually seen in this kind of activists [20], others stated that "conventional mass media will soon be dead" and that "we are the new thing". They prefer to publish their content directly on the network without any filter, so they are able to talk about their topics of interest that are ignored in the mainstream media. On the other hand many of the activists that were interviewed were collaborating or considering to collaborate with conventional media in some way such as participating in interviews, television debates, publishing opinion articles or political analyses. They integrate their collaborations in those means as another communicative element in they communication network, re-using video clips from their interventions on television on Twitter and YouTube, pointing their followers to their articles on online newspapers and pointing their newspaper readers to their set of social networks.

When asked about their possible desire to pursue jobs as journalists, in general, they don't see a career in the press or television as a viable option as they remark that they would lose their ability to perform critical thinking, their authenticity and they'll probably work under poor economical conditions, so they are better going by themselves. Their publication style is generally def fined by liquidity and eclecticism as it is common amongst the millennial's [24]. They generally don't tie themselves to a particular newspaper or television, conversely they rapidly switch between different means on convenience to maximize their visibility and to choose the media that better aligns with their 
political views. They try to diversify their publications as well as their content on social media among different sites whenever possible to maximize their visibility, avoid platform/media site dependency and to protect their online presence as they fear that one platform may fall in disgrace in the future or their profiles may be prone to censorship or any form of attack.

\subsection{Relationship with political parties}

Political parties, specially the traditional ones, have been seen as corrupt and useless structures ruled by financial powers and not serving the general interest of the people. That point of view was particularly developed and defended by the Indignados in Spain and by other platforms worldwide such as the Occupy movement [25] [7]. The Spanish influencer-activists that were interviewed in this research do somehow inherit most of those opinions from the previous wave of activists. Though their way of thinking is similar in relation to the political parties they don't deny them totally. For a better comprehension of their relationship with political parties we ask the following question:

\section{RQ6: How does an influencer-activist interact with political parties?}

Even though they don't want to get involved in the internal structure of the party, they consider eventual collaborations that may allow them to keep their ideological independence while trying to incorporate key issues of their activism into the programs of those parties. New political organisations characterized by more a populist rhetoric, started after the $15 \mathrm{~m}$ protest usually try to incorporate them into their political communication strategies. As one of the interviewees stated:

"I don't see myself as an active member of a political party though I have had some offers. If someday I decided to do something I'd prefer to be an independent candidate I don't want them to limit what I say here on YouTube." Subject 17, communist

While it is clear that some of the activists that have been interviewed are considering if not actively seeking professional opportunities related to their political activities (such as jobs as political analysts in think tanks, campaigners or lobbyists) they show a clear preference for their own ideological autonomy stating that if they had to join a political group as a grassroots militant their discourse would then be controlled and censored by the political organization thus loosing originality and therefore loosing traction with their audiences. Most of them prefer the position of the pseudo-independent pundit or even candidate that has a clear political position but remains out of the control of the political organization. 


\section{Discussion}

Many of the studies focused on comprehending the new forms of political communication in online social networks are either quantitative and based on big data sets of Twitter only or very focused on a particular case study. Trying to understand such a complex phenomenon by solely using quantitative methods like social network analysis techniques without a previous deep qualitative study may lead to incorrect or incomplete interpretations. The influenceractivist is a complex figure that moves in a network of online social networks, communication platforms and overall digital tools. While it is to some degree similar to the more traditional and well document figure of the cyber-activist, it has its own set dynamics and discourses tied to the possibilities of online social networks and the new forms of political participation. We can also appreciate some general patterns in their behavior such as a strong ideological independence, platform diversification and inter-relation, less structured relationships with other activists and a will to professionalize their activism to some degree. But some of the activists may present slightly different visions as well as their own features, thus deeper studies focused on particular kinds of influenceractivists such as left-wing or far-right for example are necessary. The variety of tools, techniques and strategies related to this new kind of activists also requires specific attention as each of the platforms presents its own dynamics and is used in a particular way. Different societies may present their own features as well, cross country studies may shed more light to this phenomenon. Quantitative methods may be very useful in defining and measuring specific network properties of these actors as well as to better define and measure their techniques and strategies.

\section{Conclusions and future work}

The traditional cyber-activist, focused on actions such as online narrative spread on forums, hashtag protests and actions on social media, leaks, change.org campaigns and offline events has evolved facilitating the rise of a new kind of activists that builds on top of it combining some of its features with the typical features of the social media influencer figure. This kind of activist is defined by a mastery of social media communication tools and strategies, a strong development of her online personal brand, a well structured and intertwined presence in a variety of platforms, each one with its own function, and a curated scheme of revenue extraction to eventually be able to self sustain her own activity.

This new emergent figure, that coexists with other forms of activism both off and online prefers not to be directly influenced or associated with conventional political organizations or the press though she may use them in an occasional and eclectic way to maximize the impact of her messages, extract revenues and specially to push her narrative into the public opinion. The influencer-activist aims at embedding herself at the centre of a networked structure on social media, to influence a large base of followers and to maximize 
her possibilities of spreading a message. They still consider offline actions such as protests and the like though they focus their efforts online and think mid to long-term about their causes as they generally aim for a change in the conscience of society about the issues they worry about that will eventually lead to political changes. As this new figure is still in the process of emergence, future work may involve the refinement of the presented definition, deeper analyses on the particular relationships these activists hold with different political organizations and mainstream medias, the set of specific tools they incorporate in their social media ecosystems and their inter-connections along with their specific communication techniques and political actions.

\section{References}

[1] Tarrow, S.: The Social Movement Society, 1st edn. Rowman Littlefield Publishers, Lanham, Maryland, Estados Unidos (1997)

[2] Goodwin, J.: The Social Movements Reader, 3rd edn. Wiley John + Sons, Hoboken, NJ, USA (2014)

[3] Donatella della Porta, M.D.: The Oxford Handbook of Social Movements, 1st edn. Oxford University Press, Oxford, UK (2016)

[4] Castells, M.: Networks of Outrage and Hope: Social Movements in the Internet Age, 1st edn. Polity, London, UK (2012)

[5] Victor Pickard, G.Y.: Media Activism in the Digital Age, 1st edn. Routledge, London, UK (2017)

[6] Stier, S., Schuenemann, W.J., Steiger, S.: Of activists and gatekeepers: Temporal and structural properties of policy networks on Twitter. NEW MEDIA \& SOCIETY 20(5), 1910-1930 (2018)

[7] Castells, M.: Communication Power, 1st edn. OUP Oxford, Oxford, UK (2011)

[8] George, J., Leidner, D.: Digital activism: a hierarchy of political commitment. (2018)

[9] Lynch, M.: After egypt: The limits and promise of online challenges to the authoritarian arab state. Perspectives on Politics 9(2), 301-310 (2011)

[10] Shirky, C.: The political power of social media: Technology, the public sphere, and political change. Foreign affairs 90(1), 28-41 (2011)

[11] Rheingold, H.: Smart Mobs: The Next Social Revolution, 1st edn. Basic books, New York, USA (2002) 
[12] Tufekci, Z.: Twitter and Tear Gas: The Power and Fragility of Networked Protest., 1st edn. Central European University Press, New haven, London (2017)

[13] Mccaughey, M., Ayers, M.: Cyberactivism: Online Activism in Theory and Practice, 1st edn. Routledge, London, UK (2003)

[14] Karatzogianni, A.: Firebrand Waves of Digital Activism 1994-2014, 1st edn. Palgrave macmillan, Camden, London (2015)

[15] Karagiannopoulos, V.: In: Owen, T., Marshall, J. (eds.) A Short History of Hacktivism: Its Past and Present and What Can We Learn from It, pp. 63-86. Springer, Cham (2021)

[16] van Dijck, J., Poell, T.: Understanding social media logic. Media and Communication 1(1) (2013)

[17] Schradie, J.: "Give me Liberty or Give me Covid-19": Anti-lockdown protesters were never Trump puppets. COMMUNICATION AND THE PUBLIC 5(3-4), 126-128 (2020)

[18] Van den Bulck, H., Hyzen, A.: Of lizards and ideological entrepreneurs: Alex Jones and Infowars in the relationship between populist nationalism and the post-global media ecology. INTERNATIONAL COMMUNICATION GAZETTE 82(1, SI), 42-59 (2020)

[19] Cooperman, R., Shufeldt, G., Conger, K.: The life of the parties: Party activists and the 2016 presidential election. PARTY POLITICS (2021)

[20] Flew, T., Iosifidis, P.: Populism, globalisation and social media. INTERNATIONAL COMMUNICATION GAZETTE 82(1, SI), 7-25 (2020)

[21] Gustafsson, N., Weinryb, N.: The populist allure of social media activism: Individualized charismatic authority. ORGANIZATION 27(3, SI), 431440 (2020)

[22] Casero-Ripolles, A.: Political influencers in the digital public sphere Introduction. COMMUNICATION \& SOCIETY-SPAIN 33(2), 171-173 (2020)

[23] van Driel, L., Dumitrica, D.: Selling brands while staying "authentic": The professionalization of instagram influencers. Convergence 27(1), 66$84(2021)$

[24] Dookhoo, S., Dodd, M.D.: Slacktivists or activists? millennial motivations and behaviors for engagement in activism. Public relations journal 13(1) (2019) 
[25] Peña-López, I., Congosto, M., Aragón, P.: Spanish indignados and the evolution of the $15 \mathrm{~m}$ movement on twitter: towards networked parainstitutions. Journal of Spanish Cultural Studies 15(1-2), 189-216 (2014)

[26] Vampa, D.: Competing forms of populism and territorial politics: the cases of vox and podemos in spain. Journal of Contemporary European Studies 28(3), 304-321 (2020)

[27] Sola, J., Rendueles, C.: Podemos, the upheaval of spanish politics and the challenge of populism. Journal of Contemporary European Studies 26(1), 99-116 (2018)

[28] Sanders, K., Berganza, R., De Miguel Pascual, R.: Spain: Populism From the Far Right to the Emergence of Podemos, pp. 249-260 (2016)

[29] Payá, P.R.: Measuring populism in spain: content and discourse analysis of spanish political parties. Journal of Contemporary European Studies 27(1), 28-60 (2019)

[30] Joyce, M.: Digital Activism Decoded: The New Mechanism of Change, 1st edn. Central European University Press, Budapest, Hungary (2010)

[31] Smith, M., Edwards-Neff, D.: Organizing for Advocacy, pp. 439-451 (2018)

[32] Lilleker, D.G., Koc-Michalska, K.: What drives political participation? motivations and mobilization in a digital age. Political Communication 34(1), 21-43 (2017)

[33] Gramsci, A.: Letters from Prison, 1st edn. Columbia University Press, Camden, London (1994)

[34] Bennett, W.L., Segerberg, A.: The logic of connective action. Information, Communication \& Society 15(5), 739-768 (2012)

[35] Chadwick, A.: The Hybrid Media System: Politics and Power, 1st edn. Oxford studies in Digital Politics, Oxford, UK (2013)

[36] Selander, L., Jarvenpaa, S.: Digital action repertories and transforming a social movement organization. MIS quarterly 40(2), 331-352 (2016)

[37] Medina Serrano, J.C., Papakyriakopoulos, O., Hegelich, S.: Dancing to the partisan beat: A first analysis of political communication on tiktok. In: 12th ACM Conference on Web Science, pp. 257-266. Association for Computing Machinery, New York, NY, USA (2020)

[38] Gilkerson, N., Berg, K.: Social Media, Hashtag Hijacking, and the Evolution of an Activist Group Strategy, pp. 141-155 (2017) 
[39] Kirkwood, G.L., Payne, H.J., Mazer, J.P.: Collective trolling as a form of organizational resistance: Analysis of the \#justiceforbradswife twitter campaign. Communication Studies 70(3), 332-351 (2019)

[40] Pickard, V.W.: Cooptation and cooperation: institutional exemplars of democratic internet technology. New Media \& Society 10(4), 625-645 (2008)

[41] Persia, F., D'Auria, D.: A survey of online social networks: Challenges and opportunities. In: 2017 IEEE International Conference on Information Reuse and Integration (IRI), pp. 614-620 (2017)

[42] Boulianne, S.: Twenty years of digital media effects on civic and political participation. Communication Research 47(7), 947-966 (2020)

[43] Castells, M.: The Rise of the Network Society vol. 1, 2nd edn. WileyBlackwell, Chichester (2010)

[44] Kidd, D.: Indymedia.org: A New Communications Commons, pp. 47-69 (2003) 